\title{
lodine-Mediated Etching of Gold Nanorods for Plasmonic ELISA Based on Colorimetric Detection of Alkaline Phosphatase
}

\author{
Zhiyang Zhang, ${ }^{\dagger, \dagger}$ Zhaopeng Chen, ${ }^{*}{ }^{\dagger}$ Shasha Wang, ${ }^{\dagger, \ddagger}$ Fangbin Cheng, ${ }^{\S}$ and Lingxin Chen ${ }^{\dagger}$
}

${ }^{\dagger}$ Key Laboratory of Coastal Environmental Processes and Ecological Remediation, Yantai Institute of Coastal Zone Research (YIC), Chinese Academy of Sciences (CAS); Shandong Provincial Key Laboratory of Coastal Environmental Processes, YICCAS, Yantai Shandong 264003, P. R. China

${ }^{\ddagger}$ University of Chinese Academy of Sciences, Beijing 100049, P. R. China

${ }^{\S}$ Ocean School, Yantai University, Yantai 264005, P. R. China

Supporting Information

ABSTRACT: Here, we propose a plasmonic enzyme-linked immunosorbent assay (ELISA) based on highly sensitive colorimetric detection of alkaline phosphatase (ALP), which is achieved by iodine-mediated etching of gold nanorods (AuNRs). Once the sandwich-type immunocomplex is formed, the ALP bound on the polystyrene microwells will hydrolyze ascorbic acid 2phosphate into ascorbic acid. Subsequently, iodate is reduced to iodine, a moderate oxidant, which etches AuNRs from rod to sphere in shape. The shape change of AuNRs leads to a blue-shift of longitudinal localized surface plasmon resonance. As a result, the solution of AuNRs changes from blue to red. Benefiting from the highly sensitive detection of ALP, the proposed plasmonic ELISA has achieved an ultralow detection limit $(100 \mathrm{pg} / \mathrm{mL})$ for human immunoglobulin G (IgG). Importantly, the visual detection limit (3.0

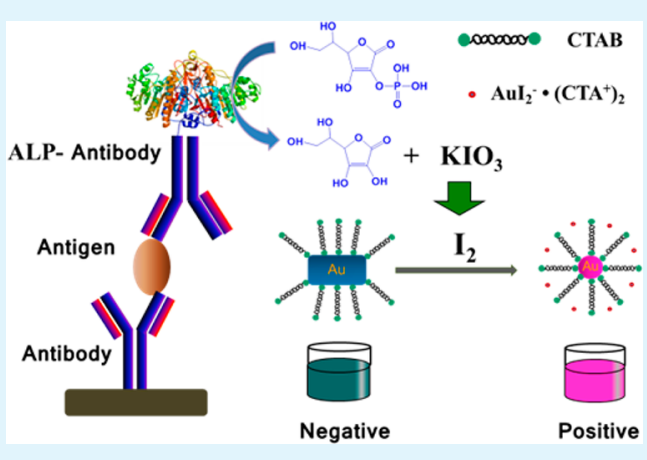
$\mathrm{ng} / \mathrm{mL}$ ) allows the rapid differential diagnosis with the naked eye. The further detection of human IgG in fetal bovine serum indicates its applicability to the determination of low abundance protein in complex biological samples.

KEYWORDS: gold nanorods, etching, iodine, alkaline phosphatase, plasmonic ELISA

\section{INTRODUCTION}

In the last two decades, gold nanoparticles (AuNPs) have received considerable attention in colorimetric sensing because of their strong localized surface plasmon resonance (LSPR) extinction in the visible light region. ${ }^{1}$ An obvious color change from red to blue can be induced by aggregation of AuNPs. This property provides a simple platform for the colorimetric sensing of various targets. ${ }^{3-7}$ However, they often suffer from strong false positive results (autoaggregation) and timeconsuming modification of AuNPs. To solve these problems, another sensing platform based on etching of gold or silver nanoparticles is proposed using the shape-dependent property of LSPR ${ }^{8-10}$ In addition, this platform allows the making of economical and stable test paper. ${ }^{11}$ Unfortunately, only a few targets have been detected using this platform. ${ }^{10-18}$ Most recently, some researchers have started to develop the nanoparticle-etching-based sensors for biomolecules by changing the shape of silver nanoprisms. ${ }^{19-21}$ The shortcoming of this method is that the shape of silver nanoprims is easily influenced by light, temperature, and biological thiol. ${ }^{22,23}$ Therefore, it is still challenging to establish a reliable strategy to expand nanoparticle-etching-based sensors.

Enzyme-linked immunosorbent assay (ELISA) is the main format of immunoassay, which is based on the antigenantibody recognition and biocatalytic property of an enzyme.
ELISA has been widely used in clinical diagnosis, environmental analysis, and food test, as well as laboratory research. ${ }^{24-27}$ In principle, ELISA can be used to detect any target if the corresponding antibody is available. Developing a nanoparticle-etching-based ELISA can expand the scope of the nanoparticle-etching-based sensors. Alkaline phosphatase (ALP) is one of the most commonly used enzyme label in ELISA due to its high catalysis activity and low cost. An efficient and effective detection method for ALP is the key to the ALP-based ELISA. For detection of ALP, even though many methods, such as fluorescence, ${ }^{28-30}$ chemiluminescence, $^{31}$ surface enhanced Raman scattering, ${ }^{32}$ and electrochemistry, ${ }^{33}$ possess high sensitivity, they often lack robustness and simplicity. In contrast, colorimetric methods are usually simple and stable, but most of them are not sensitive. ${ }^{34-38}$

In this work, we propose a plasmonic ELISA based on highly sensitive colorimetric detection of ALP, which is achieved by iodine-mediated etching of gold nanorods (AuNRs). As the intermediate of enzyme-triggered reaction, iodine etches AuNRs into $\mathrm{Au}(\mathrm{I})$ and leads to a blue-shift of LSPR of AuNRs. The peak shift can be used for quantification of human

Received: August 9, 2015

Accepted: November 30, 2015

Published: November 30, 2015 
immunoglobulin G (IgG), which is chosen as a model protein in this work. The detection limit to IgG is calculated to be 100 $\mathrm{pg} / \mathrm{mL}$, which is much lower than that of other similar methods ${ }^{39-41}$ and even comparable with the results obtained from many sensitive electrochemical methods. ${ }^{42-45}$ The successful detection of human IgG in fetal bovine serum indicates that this method is applicable to the determination of low abundance protein in complex biological samples.

\section{RESULTS AND DISCUSSION}

Principle for lodine-Mediated Etching of AuNRs. The absorption spectra in Figure 1 show the responses of AuNRs to
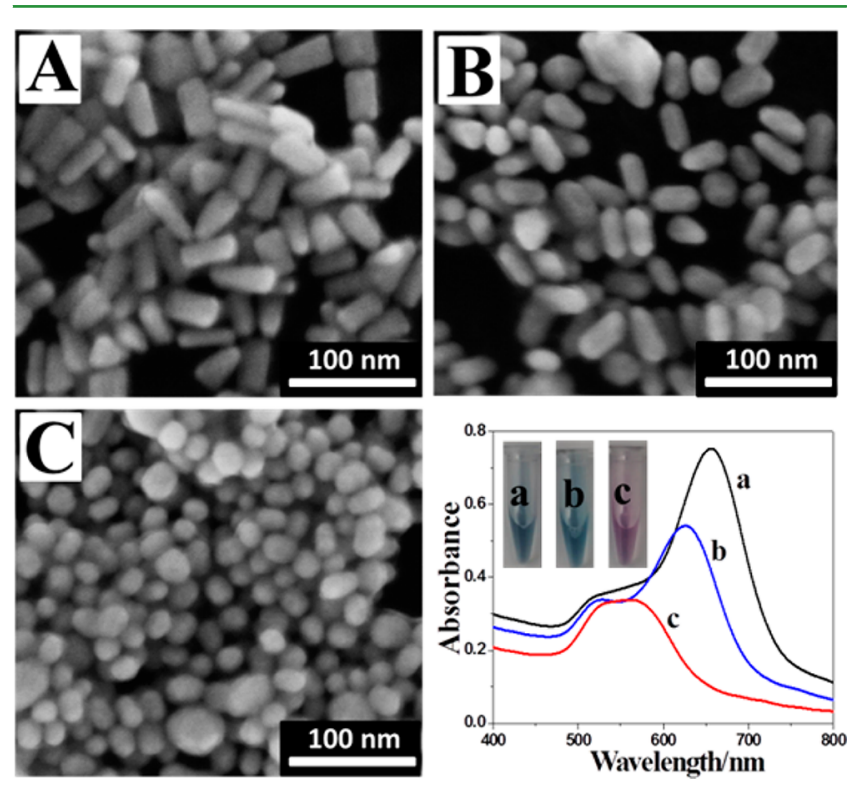

Figure 1. SEM (scanning electron microscopy) images (A-C) and absorption spectra (color inset) of AuNRs after incubation with 0 (A, a), $10(\mathrm{~B}, \mathrm{~b})$ and $30(\mathrm{C}, \mathrm{c}) \mu \mathrm{M} \mathrm{I}_{2}$ in glycine/ $\mathrm{HCl}$ buffer solution $(\mathrm{pH}$ 2.2, $50 \mathrm{mM}$ ) containing $10 \mathrm{mM} \mathrm{CTAB}, 1.0 \mathrm{mM} \mathrm{I}^{-}$.

0 (curve a), 10 (curve b), and 30 (curve c) $\mu \mathrm{M} \mathrm{I}_{2}$ in the presence of $\mathrm{I}^{-}$and cetyltrimethylammonium ions $\left(\mathrm{CTA}^{+}\right)$. With the increase in $\mathrm{I}_{2}$ concentration, the longitudinal LSPR shifts to shorter wavelength gradually, which is attributed to the decrease in aspect ratio of AuNRs (SEM images A-C in Figure 1). ${ }^{46}$ Although the iodine-induced morphological change of AuNRs has been widely reported, the mechanism for this phenomenon has not reached a consensus. ${ }^{47-49}$ On the basis of our results, we propose a new mechanism of $\mathrm{CTA}^{+}$-assisted oxidation of gold. The reaction is proposed as follows:

$$
2 \mathrm{Au}+\mathrm{I}_{2}+2 \mathrm{I}^{-}+4 \mathrm{CTA}^{+} \rightarrow 2 \mathrm{AuI}_{2}{ }^{-}-\left(\mathrm{CTA}^{+}\right)_{2}
$$

To verify the hypothesis, we added a high concentration of $\mathrm{I}_{2}$ $(1.0 \mathrm{mM})$ to the concentrated gold nanorods solution $(2.8$ $\mathrm{nM})$. After incubation at $50{ }^{\circ} \mathrm{C}$ for $10 \mathrm{~min}$, the solution became colorless, indicating that the product is $\mathrm{Au}(\mathrm{I}) .{ }^{11}$ Then, the obtained solution was measured to record the mass spectrum. A full mass spectrum can be seen in Figure 2. Peaks corresponding to five components of the etching of AuNRs are present: $\mathrm{CTA}^{+}$at $m / z 284.52, \mathrm{Cl}^{-}-\left(\mathrm{CTA}^{+}\right)_{2}$ at $m / z 603.46$, $\mathrm{Br}^{-}-\left(\mathrm{CTA}^{+}\right)_{2}$ at $m / z$ 649.2, $\mathrm{I}^{-}-\left(\mathrm{CTA}^{+}\right)_{2}$ at $m / z$ 695.29, and $\mathrm{AuI}_{2}{ }^{-}-\left(\mathrm{CTA}^{+}\right)_{2}$ at $m / z 1018.88$. This result indicates that the product in this reaction is $\mathrm{AuI}_{2}^{-}-\left(\mathrm{CTA}^{+}\right)_{2}$, which directly validates the reaction equation mentioned above.

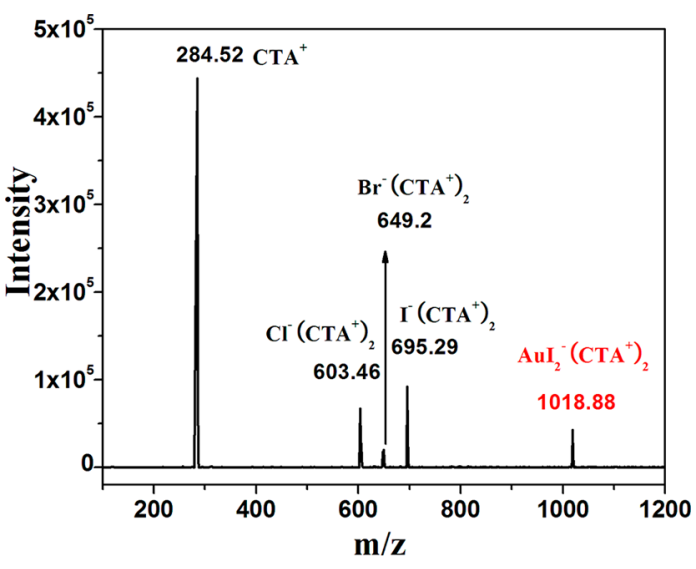

Figure 2. Mass spectrum of AuNRs solution (2.8 nM) after incubation with $1.0 \mathrm{mM} \mathrm{I}_{2}$ in glycine/ $\mathrm{HCl}$ buffer solution containing $10 \mathrm{mM}$ CTAB, $1.0 \mathrm{mM} \mathrm{I}^{-}$.

To further confirm the accelerative role of $\mathrm{CTA}^{+}$in the etching process, several control experiments were conducted. The addition of $1.0 \mathrm{mM} \mathrm{CTAB}$ or CTAC greatly increased the etching of tween 20-stabilized gold, whereas the addition of 1.0 $\mathrm{mM} \mathrm{NaBr}$ or $\mathrm{NaCl}$ had little effect on the etching process (Figure S1A). These results are consistent with our previous reports. ${ }^{11,17}$ Experimental results also indicate that $\mathrm{CTA}^{+}$and $\mathrm{I}^{-}$(halide ions) have synergy effects on the etching of gold nanoparticles (Figure S1B).

Theoretically, the etching product is dependent on both the reduction potential of $\mathrm{Au}(\mathrm{I})$ halide/ $\mathrm{Au}$ and the concentration of halide ions. On the one hand, the reduction potential of $\mathrm{AuI}_{2}{ }^{-} / \mathrm{Au}(0.578 \mathrm{~V}$ vs $\mathrm{NHE})$ is much lower than that of $\mathrm{AuBr}_{2}{ }^{-} / \mathrm{Au}(0.959 \mathrm{~V}$ vs $\mathrm{NHE})$ and $\mathrm{AuCl}_{2}^{-} / \mathrm{Au}(1.154 \mathrm{~V}$ vs $\mathrm{NHE}$ ). These values well explain that the main product in this reaction is $\mathrm{AuI}_{2}{ }^{-}\left(\mathrm{CTA}^{+}\right)_{2}$, but not $\mathrm{AuCl}_{2}{ }^{-}-\left(\mathrm{CTA}^{+}\right)_{2}(\mathrm{~m} / z$ 836) or $\mathrm{AuBr}_{2}{ }^{-}-\left(\mathrm{CTA}^{+}\right)_{2}(\mathrm{~m} / z$ 924.52). On the other hand, the concentration of halide ions has a great effect on the product. For example, when the $\mathrm{Br}^{-}$concentration is much higher than $\mathrm{I}^{-}$(Figure S4, Supporting Information), the $\mathrm{AuBr}_{2}{ }^{-}-\left(\mathrm{CTA}^{+}\right)_{2}$ will become the domain product.

lodine-Mediated Etching of AuNRs for Sensing of Reducing Targets. Normally, reducing agents are used to reduce gold ions into gold nanoparticles. However, in this work, the presence of reducing agents can conversely induce the oxidation of the gold nanoparticles into gold ions. Scheme S1 (Supporting Information) schematically shows the strategy for sensing of reducing targets based iodine-mediated etching of AuNRs. $\mathrm{KIO}_{3}$ is first transformed into $\mathrm{I}_{2}$ by reducing targets, and then the produced $\mathrm{I}_{2}$ further oxidizes $\mathrm{Au}$ into $\mathrm{Au}(\mathrm{I})$. As a result, the longitudinal LSPR of AuNRs shifts to short wavelength. Several normal reducing targets including $\mathrm{S}^{2-}, \mathrm{I}^{-}$, $\mathrm{S}_{2} \mathrm{O}_{3}{ }^{2-}$, o-dihydroxybenzene, hydrazine hydrate, and ascorbic acid (AA) were tested using this sensing strategy. As shown in Figure S2 (Supporting Information), the LPSR peak does not change in the presence of $\mathrm{KIO}_{3}$ and CTAB (curve a). This is because $\mathrm{IO}_{3}{ }^{-}$can hardly react with $\mathrm{Br}^{-}$under the conditions. Otherwise, the AuNRs would be etched by the produced $\mathrm{Br}_{2}$, accompanied by a blue-shift of LSPR. In contrast, the presence of $10 \mu \mathrm{M}$ concentration of these reducing targets induces a large peak shift of logitudinal LSPR (about $50 \mathrm{~nm}$ ) owing to the etching of AuNRs by the produced $I_{2}$ (curves $b-f$ ).

To demonstrate the production of $\mathrm{I}_{2}$, the UV/vis spectra of $\mathrm{KIO}_{3}$ solution in the presence of different substances were 
measured (Figure S3, Supporting Information). $\mathrm{KIO}_{3}$ produced negligible absorption (curve a), and the solution appeared colorless. The addition of AA resulted in a big absorption in the range from 400 to $550 \mathrm{~nm}$ (curve $\mathrm{b}$ ) and the solution changed into yellow, suggesting the production of large amounts of $I_{2}$. The yellow solution turned to dark blue after addition of starch (photo d), which further indicates that large amounts of $\mathrm{I}_{2}$ were produced.

On the basis of the above results and our previous work, ${ }^{11,50}$ the reaction for the AA-induced etching of AuNRs can be described as follows:

$$
5 \mathrm{C}_{6} \mathrm{H}_{8} \mathrm{O}_{6}+2 \mathrm{IO}_{3}^{-}+2 \mathrm{H}^{+} \rightarrow 5 \mathrm{C}_{6} \mathrm{H}_{6} \mathrm{O}_{6}+\mathrm{I}_{2}+6 \mathrm{H}_{2} \mathrm{O}
$$

$$
\begin{aligned}
2 \mathrm{Au} & +\mathrm{I}_{2}+4 \mathrm{CTA}^{+} \\
& \rightarrow \mathrm{AuI}_{2}{ }^{-}-\left(\mathrm{CTA}^{+}\right)_{2}+\mathrm{AuI}_{2}{ }^{-}-\left(\mathrm{CTA}^{+}\right)_{2}
\end{aligned}
$$

Although this sensing strategy doses not have specficity for certain targets, it is still possible to detect some targets under given conditions, such as $\mathrm{H}_{2} \mathrm{~S}$ in the air. ${ }^{51}$ More importantly, this strategy provides an indirect sensing method for some targets via a reducing intermediate.

Colorimetric Sensing of ALP. Inspired by the above results, we developed a colorimetric method for sensing of ALP. Figure $3 \mathrm{~A}$ shows the sensing mechanism for the colorimetric
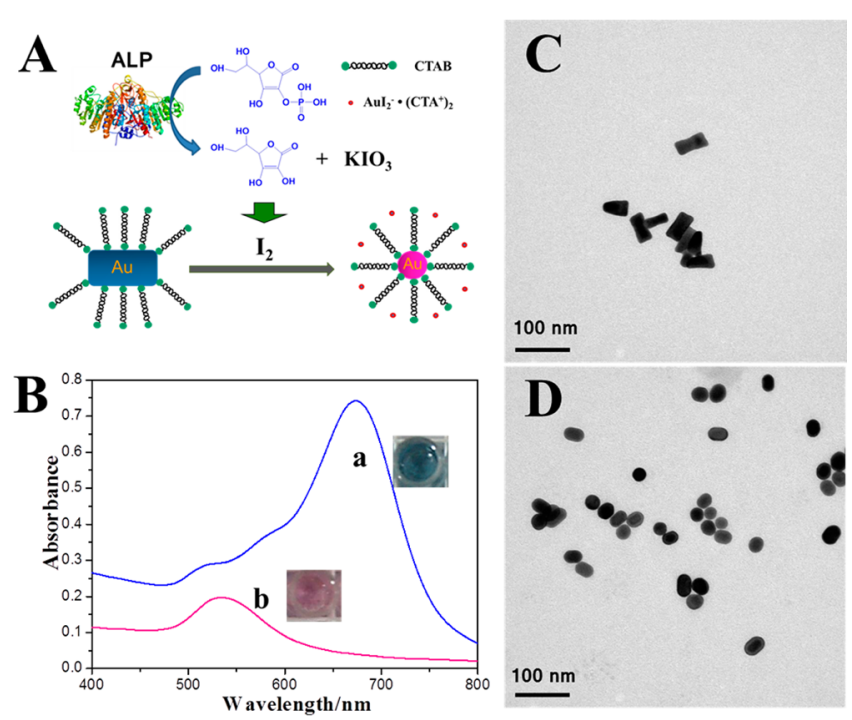

Figure 3. (A) Schematic illustration for colorimetric detection of ALP based on etching of AuNRs. (B) Absorption spectra and optical images of AuNRs before (curve a, blue image) and after (curve b, red image) incubation with $10 \mathrm{U} / \mathrm{L}$ of ALP. TEM (transmission electron microscope) images of the AuNRs (C) before and (D) after treatment with ALP separately.

detection of ALP. ALP hydrolyzes ascorbic acid 2-phosphate (AA-p) into AA due to the dephosphorylation. Subsequently, AA induces the etching of AuNRs in the presence of $\mathrm{KIO}_{3}$ (images $\mathrm{C}$ and $\mathrm{D}$ in Figure 3). As a result, the etching leads to the blue-shift of longitudinal LSPR with a significant color change from blue to red (Figure 3B). This color change provides a visual sensing method for ALP. It is worth noting that the high stability and unique optical property of AuNRs plays an important role for the visual detection. Zeta potential and dynamic light scattering (DLS) of AuNRs in the buffer solution indicate that the AuNRs can keep stable in the sensing system (Figure S5, Supporting Information). In addition, the maximum absorption of the used AuNRs also benefits the visual detection. The aspect ratio (length/width $\approx 2: 1$ ) of the used AuNRs results in a maximum absorption at $660 \mathrm{~nm}$, which is close to the center of the visible range $(390-780 \mathrm{~nm})$. Therefore, the color of the used AuNRs is very senstive to human eyes.

According to the mechanism, the sensing performance of ALP is directly dependent on the sensitivity for detection of AA. Thus, the AA sensing conditions, including $\mathrm{pH}$, concentration of $\mathrm{Br}^{-}$, incubation temperature, and time, were first optimized (Figures S6-S9). It should be noted here that the addition of $\mathrm{Br}^{-}$to the sensing system improved the sensitivity greatly (Figure S7). MS experiment showed that the component of $\mathrm{AuI}_{2}^{-}-\left(\mathrm{CTA}^{+}\right)_{2}$ almost disappeared, accompanied by the appearance of a new component, $\mathrm{AuI}_{2}{ }^{-}-$ $\left(\mathrm{CTA}^{+}\right)_{2}$ (Figure S4). The formation of $\mathrm{AuI}_{2}^{-}-\left(\mathrm{CTA}^{+}\right)_{2}$ is probably attributed to the replacement reaction, as shown in reaction 3. The formation of $\mathrm{AuI}_{2}^{-}-\left(\mathrm{CTA}^{+}\right)_{2}$ decreases the reduction potential of $\mathrm{Au}(\mathrm{I}) / \mathrm{Au}$ further and, therefore, makes the oxidation of AuNRs more thorough. Under optimal experimental conditions, the responses of the AuNRs to different concentrations of AA were tested (Figure S10). A linear relationship between the absorbance at $670 \mathrm{~nm}\left(A_{670 \mathrm{~nm}}\right)$ and AA concentrations from 0.1 to $0.8 \mu \mathrm{M}$ was obtained. The detection limit was calculated as $0.1 \mu \mathrm{M}(1.0 \mu \mathrm{M}$ for visual detection limit) according to the $3 \sigma$ rule.

$$
\mathrm{AuI}_{2}{ }^{-}-\left(\mathrm{CTA}^{+}\right)_{2}+2 \mathrm{Br}^{-} \rightarrow \mathrm{AuI}_{2}^{-}-\left(\mathrm{CTA}^{+}\right)_{2}+2 \mathrm{I}^{-}
$$

The high sensitivity for AA provides a good prerequisite for ALP detection. After optimizing the substrate (AA-p) concentration and bioreaction time (Figures S11 and S12), we investigated the sensing performance for the colorimetric sensing of ALP. As shown in Figure 4A, the solution changes gradually from blue to red with the increase in ALP concentration. The obvious color changes comes from the change in the absoption spectra of AuNRs. As shown in Figure $4 \mathrm{~B}$, the $A_{670 \mathrm{~nm}}$ decreases with increasing ALP concentration (Figure S13) and there is a linear relationship between $A_{670 \mathrm{~nm}}$ and ALP concentrations in the range from 0.01 to $0.4 \mathrm{U} / \mathrm{L}$ (Figure 4C). A detection limit of $0.01 \mathrm{U} / \mathrm{L}$ is calculated based on the $3 \sigma$ rule. To the best of our knowledge, the limit of detection is among the lowest reported for the nanoparticlebased colorimetric detection methods (Table 1). ${ }^{34-38}$

As mentioned above, the sensing strategy doses not have specificity for certain reducing agents. Interferences, such as dopamine, adrenaline, and AA, will hinder the direct sensing of ALP in biological samples. In consideration of the successful application of ALP in ELISA, the high sensitivity for sensing of ALP probably is of great benefit to improve the sensitivity of ALP-labeled sandwich ELISA. (The sensitivity of sandwich immunoassay can be increased by using a tracer with higher detectability. The factors that determine the ultimate sensitivity of competitive immunoassays are the antibody affinity constant and the experimental errors, but not the detectability of tracer. ${ }^{52}$ )

Plasmonic ELISA with the Naked Eye. Figure 5A schematically illustrates the mechanism of the visual plasmonic sandwich ELISA. ALP was used as the readout enzyme, and AA-p was chosen as the substrate. After formation of a sandwich-type immunocomplex, the ALP bound on the polystyrene microwells triggers iodine-mediated etching of AuNRs accompanied by a color change from blue to red. 

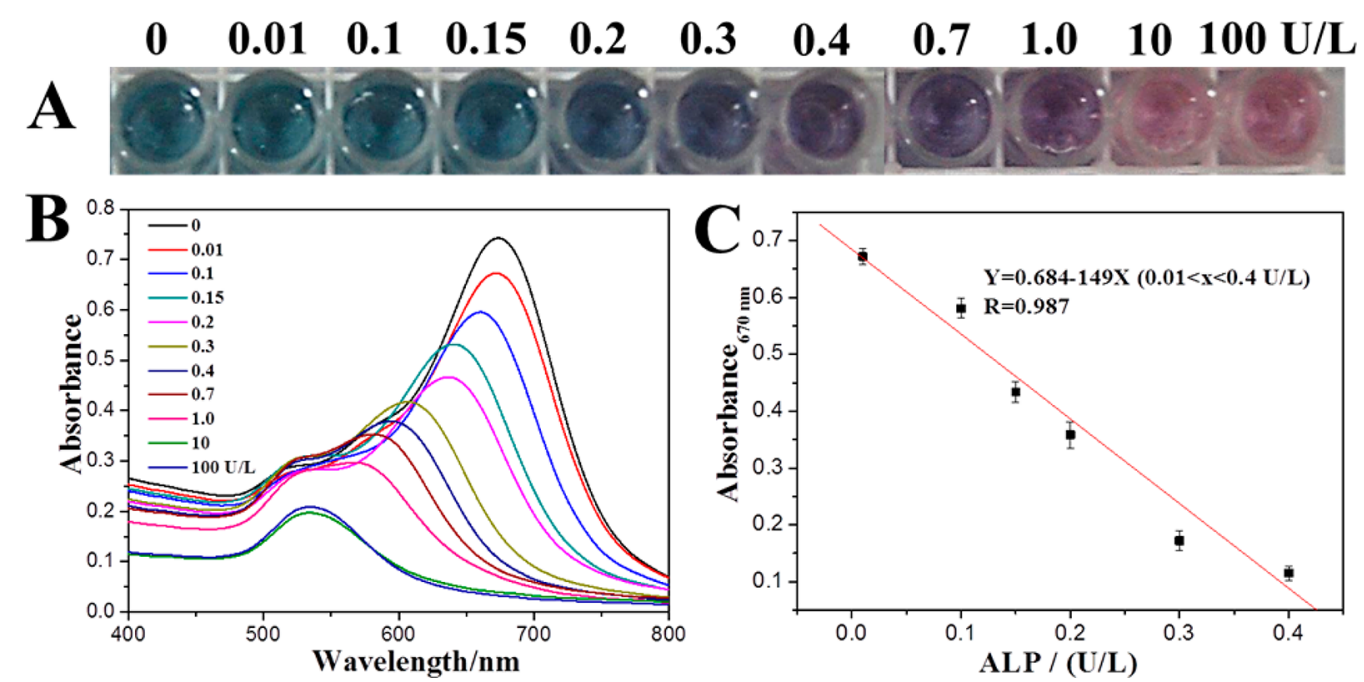

Figure 4. (A) Color changes and (B) absorption spectra of AuNRs after incubation with different concentrations of ALP. (C) Linear relationship between logitudinal LSPR of AuNRs and ALP concentrations.

Table 1. Comparison of the Performance of Different Plasmonic Sensors for ALP

$\begin{array}{cc}\text { method } & \text { material } \\ \text { colorimetry } & \text { AuNPs } \\ \text { colorimetry } & \text { AuNPs } \\ \text { colorimetry } & \text { AuNPs } \\ \text { colorimetry } & \text { AuNPs } \\ \text { colorimetry } & \text { AuNRs } \\ \text { colorimetry } & \text { AuNRs }\end{array}$

mechanism
nanoparticle aggregation
nanoparticle aggregation
nanoparticle aggregation
nanoparticle aggregation
growth of AuNRs@Ag
etching of AuNRs

detection limit
$1.7 \mu \mathrm{M}$
$8000 \mathrm{U} / \mathrm{L}$
$10 \mathrm{U} / \mathrm{L}$
$0.2 \mathrm{U} / \mathrm{L}$
$3.3 \mathrm{U} / \mathrm{L}$
$0.01 \mathrm{U} / \mathrm{L}$

signal coming from nanoparticles autoaggregation, ${ }^{37,54}$ as the

Here, human IgG was chosen as a model analyte in the proposed plasmonic ELISA. The photos in Figure 5B show the responses of AuNRs to different concentrations of human IgG. The solution turned from blue to red gradually with the increase in human IgG concentration. The naked-eye detectable limit for human IgG is as low as $3 \mathrm{ng} / \mathrm{mL}$, allowing the rapid diagnosis with the naked eye. In contrast, the multiple color changes in this method are much easier to distinguish than the single color change which was used in the ALP-based commercial ELISA kit. Figure S14 (Supporting Information) shows the absorption spectra of AuNRs in the presence of different concentrations of human IgG. Two parameters can be used for quantification of human IgG: the absorbance at 670 $\mathrm{nm}$, and the peak shift of logitudinal LSPR. A linear relationship was obtained between the absorbance at $670 \mathrm{~nm}$ and logarithm of human IgG concentrations in the range from 0.1 to $10 \mathrm{ng} /$ $\mathrm{mL}$ (Figure S15, Supporting Information). This linear relationship can be only used for the low concentration range from 0 to $10 \mathrm{ng} / \mathrm{mL}$. By comparison, using peak shift, two different linear relationships could be obtained, respectively: one between the peak shift and human IgG concentrations $(0.1-10 \mathrm{ng} / \mathrm{mL})$ and the other between the peak shift and logarithm of human IgG concentrations $(10-10000 \mathrm{ng} / \mathrm{mL}$ ) (Figure 5B). According to the $3 \sigma$ rule, the detection limit for human $\operatorname{IgG}$ is calculated to be $100 \mathrm{pg} / \mathrm{mL}$, which is at least 1 order of magnitude lower than that of other plasmonic methods ${ }^{39-41}$ and even comparable with the results obtained from many sensitive electrochemical methods. ${ }^{42-45}$ Additionally, compared to other nanoparticle-based ELISA methods, this method also exhibits many advantages: (1) it is easier to adapt to the conventional ELISA platforms directly, since ALP-labeled antibodies are commercially available; ${ }^{21,45,53,54}(2)$ there is no false positive signal does not come from nanoparticle aggregation; (3) it is label-free for AuNRs, making it much easier to operate; ${ }^{37,54}$ and (4) AuNRs are much more stable to light, temperature, and biological thiol than silver nanoprims. ${ }^{21,22}$

Determination of Human IgG in Fetal Bovine Serum. It is important to detect low concentrations of proteins (e.g., biomarkers) in biological samples with the presence of an abundance of other proteins. Since the normal concentration of human IgG in serum reaches $\mathrm{mg} / \mathrm{mL}$ levels, the direct detection of human IgG in human serum cannot show the applicability of low abundant protein detection in biological samples. In consideration of the similar component and concentration in mammals (including humans), the applicability of the proposed plasmonic ELISA was evaluated by the analysis of low concentrations of human IgG spiked in fetal bovine serum. As the fetal bovine serum contains many potential interferences such as proteins, salt, and other small molecules (including glucose, ascorbic acid, etc.), the resistance to interferences can be also tested by this assay at the same time. The recoveries of the spiked human IgG ranged from $83.3 \%$ to $103.8 \%$ (Table 2 ). The results indicate that such a method is applicable to the quantification of low abundant protein in complex biological samples, avoiding the interference from protein, salt, and other small molecules.

\section{CONCLUSION}

In conclusion, we present a plasmonic ELISA based on colorimetric detection of ALP using iodine-mediated etching of AuNRs. Benefiting from the excellent sensing performance for ALP with a detection limit of $10 \mathrm{mU} / \mathrm{L}$, the visual plasmonic ELISA achieved a naked-eye detectable limit of $3 \mathrm{ng} / \mathrm{mL}$ of 


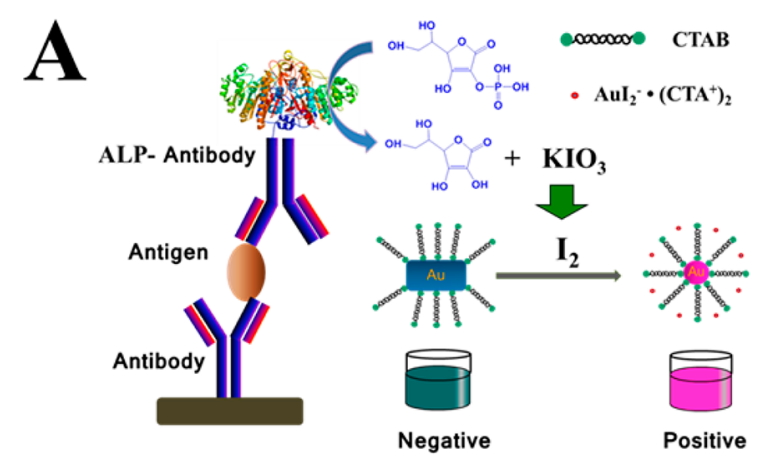

$\begin{array}{lllllllllll}0 & 0.1 & 0.5 & 1.0 & 3.0 & 5.0 & 7.0 & 10 & 10^{2} & 10^{3} & \mathrm{ng} / \mathrm{mL}\end{array}$

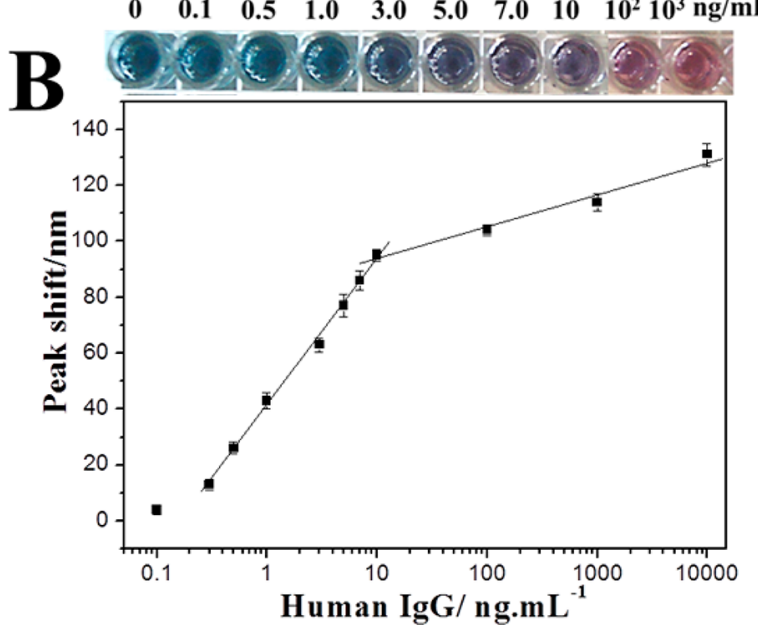

Figure 5. (A) Schematic illustration for visual plasmonic ELISA based on ALP-triggered etching of AuNRs. (B) Color of AuNRs after incubation with different concentrations of human IgG and linear relationship between the peak shift of AuNRs and human IgG concentrations.

Table 2. Determination of Human IgG in Simulated Biological Samples

\begin{tabular}{ccccc} 
sample & spiked $(\mathrm{ng} / \mathrm{mL})$ & detected $(\mathrm{ng} / \mathrm{mL})$ & recovery $(\%)$ & RSD (\%) \\
1 & 1.0 & 0.833 & 83.3 & 13.8 \\
2 & 7.0 & 6.4 & 91.4 & 8.2 \\
3 & 100.0 & 103.8 & 103.8 & 5.5 \\
\hline
\end{tabular}

human IgG. The detection limit is much lower than that of other similar methods. In addition, this method is able to avoid some disadvantages in other plasmonic ELISA methods, such as additional modification of antibodies, autoaggregation, labeling of nanoparticles, and low stability. The successful detection of human IgG in fetal bovine serum indicates that it is feasible for the proposed method to detect low abundance protein in complex biological samples. From the perspective of principle, we certify a $\mathrm{CTA}^{+}$-assisted etching mechanism of AuNRs, giving a better understanding of the intrinsic principle for the oxidation of AuNRs.

\section{ASSOCIATED CONTENT}

\section{S Supporting Information}

The Supporting Information is available free of charge on the ACS Publications website at DOI: 10.1021/acsami.5b07344.

Experimental detail information for synthesis of gold nanorods and detecting procedures, figures for etching proof and optimization of experimental conditions, and scheme for the reducing target sensing (PDF)

\section{AUTHOR INFORMATION}

\section{Corresponding Author}

*E-mail: zhpchen@yic.ac.cn. Fax/Phone: 086-535-2109133.

Notes

The authors declare no competing financial interest.

\section{ACKNOWLEDGMENTS}

The research was financially supported by the Department of Science and Technology of Shandong Province (BS2009DX006), NSFC (no. 21575159, 21275158) and the Strategic Priority Research Program of the Chinese Academy of Sciences (XDA11020702).

\section{REFERENCES}

(1) Ghosh, S. K.; Pal, T. Interparticle Coupling Effect on the Surface Plasmon Resonance of Gold Nanoparticles: from Theory to Applications. Chem. Rev. 2007, 107 (11), 4797-4862.

(2) Saha, K.; Agasti, S. S.; Kim, C.; Li, X.; Rotello, V. M. Gold Nanoparticles in Chemical and Biological Sensing. Chem. Rev. 2012, 112 (5), 2739-2779.

(3) Elghanian, R.; Storhoff, J. J.; Mucic, R. C.; Letsinger, R. L.; Mirkin, C. A. Selective Colorimetric Detection of Polynucleotides Based on the Distance-Dependent Optical Properties of Gold Nanoparticles. Science 1997, 277 (5329), 1078-1081.

(4) Sato, K.; Hosokawa, K.; Maeda, M. Rapid Aggregation of Gold Nanoparticles Induced by Non-Cross-Linking DNA Hybridization. J. Am. Chem. Soc. 2003, 125 (27), 8102-8103.

(5) Thanh, N. T. K.; Rosenzweig, Z. Development of An Aggregation-Based Immunoassay for Anti-Protein A Using Gold Nanoparticles. Anal. Chem. 2002, 74 (7), 1624-1628.

(6) Li, H.; Rothberg, L. Colorimetric Detection of DNA Sequences Based on Electrostatic Interactions with Unmodified Gold Nanoparticles. Proc. Natl. Acad. Sci. U. S. A. 2004, 101 (39), 14036-14039.

(7) Lee, J. S.; Han, M. S.; Mirkin, C. A. Colorimetric Detection of Mercuric Ion $\left(\mathrm{Hg}^{2+}\right)$ in Aqueous Media Using DNA-Functionalized Gold Nanoparticles. Angew. Chem. 2007, 119 (22), 4171-4174.

(8) Chen, H.; Kou, X.; Yang, Z.; Ni, W.; Wang, J. Shape-and SizeDependent Refractive Index Sensitivity of Gold Nanoparticles. Langmuir 2008, 24 (10), 5233-5237.

(9) Nehl, C. L.; Hafner, J. H. Shape-Dependent Plasmon Resonances of Gold Nanoparticles. J. Mater. Chem. 2008, 18 (21), 2415-2419.

(10) Chen, Y.-Y.; Chang, H.-T.; Shiang, Y.-C.; Hung, Y.-L.; Chiang, C.-K.; Huang, C.-C. Colorimetric Assay for Lead Ions Based on the Leaching of Gold Nanoparticles. Anal. Chem. 2009, 81 (22), 94339439.

(11) Zhang, Z.; Chen, Z.; Qu, C.; Chen, L. Highly Sensitive Visual Detection of Copper Ions Based on the Shape-Dependent LSPR Spectroscopy of Gold Nanorods. Langmuir 2014, 30 (12), 36253630.

(12) Saa, L.; Coronado-Puchau, M.; Pavlov, V.; Liz-Marzán, L. M. Enzymatic Etching of Gold Nanorods by Horseradish Peroxidase and Application to Blood Glucose Detection. Nanoscale 2014, 6 (13), 7405-7409.

(13) Lou, T.; Chen, L.; Chen, Z.; Wang, Y.; Chen, L.; Li, J. Colorimetric Detection of Trace Copper Ions Based on Catalytic Leaching of Silver-Coated Gold Nanoparticles. ACS Appl. Mater. Interfaces 2011, 3 (11), 4215-4220.

(14) Shang, L.; Jin, L.; Dong, S. Sensitive Turn-On Fluorescent Detection of Cyanide Based on the Dissolution of Fluorophore Functionalized Gold Nanoparticles. Chem. Commun. 2009, 21 (21), 3077-3079.

(15) Tripathy, S. K.; Woo, J. Y.; Han, C.-S. Highly Selective Colorimetric Detection of Hydrochloric Acid Using Unlabeled Gold 
Nanoparticles and An Oxidizing Agent. Anal. Chem. 2011, 83 (24), 9206-9212.

(16) Li, F.-M.; Liu, J.-M.; Wang, X.-X.; Lin, L.-P.; Cai, W.-L.; Lin, X.; Zeng, Y.-N.; Li, Z.-M.; Lin, S.-Q. Non-Aggregation Based Label Free Colorimetric Sensor for the Detection of Cr (VI) Based on Selective Etching of Gold Nanorods. Sens. Actuators, B 2011, 155 (2), 817-822.

(17) Chen, Z.; Zhang, Z.; Qu, C.; Pan, D.; Chen, L. Highly Sensitive Label-Free Colorimetric Sensing of Nitrite Based on Etching of Gold Nanorods. Analyst 2012, 137 (22), 5197-5200.

(18) Zhang, Z.; Chen, Z.; Pan, D.; Chen, L. Fenton-Like ReactionMediated Etching of Gold Nanorods for Visual Detection of $\mathrm{Co}^{2+}$. Langmuir 2015, 31 (1), 643-650.

(19) Malile, B.; Chen, J. I. Morphology-Based Plasmonic Nanoparticle Sensors: Controlling Etching Kinetics With Target-Responsive Permeability Gate. J. Am. Chem. Soc. 2013, 135 (43), 16042-16045.

(20) Xia, Y.; Ye, J.; Tan, K.; Wang, J.; Yang, G. Colorimetric Visualization of Glucose at the Submicromole Level in Serum by a Homogenous Silver Nanoprism-Glucose Oxidase System. Anal. Chem. 2013, 85 (13), 6241-6247.

(21) Yang, X.; Yu, Y.; Gao, Z. A Highly Sensitive Plasmonic DNA Assay Based on Triangular Silver Nanoprism Etching. ACS Nano 2014, 8 (5), 4902-4907.

(22) Tang, B.; Xu, S.; Hou, X.; Li, J.; Sun, L.; Xu, W.; Wang, X. Shape Evolution of Silver Nanoplates Through Heating and Photoinduction. ACS Appl. Mater. Interfaces 2013, 5 (3), 646-653.

(23) Li, Y.; Li, Z.; Gao, Y.; Gong, A.; Zhang, Y.; Hosmane, N. S.; Shen, Z.; Wu, A. Red-to-Blue" Colorimetric Detection of Cysteine via Anti-Etching of Silver Nanoprisms. Nanoscale 2014, 6 (18), 1063110637.

(24) Chikkaveeraiah, B. V.; Bhirde, A. A.; Morgan, N. Y.; Eden, H. S.; Chen, X. Electrochemical Immunosensors for Detection of Cancer Protein Biomarkers. ACS Nano 2012, 6 (8), 6546-6561.

(25) Feng, S.; Caire, R.; Cortazar, B.; Turan, M.; Wong, A.; Ozcan, A. Immunochromatographic Diagnostic Test Analysis Using Google Glass. ACS Nano 2014, 8 (3), 3069-3079.

(26) Anderson, G. P.; Lamar, J. D.; Charles, P. T. Development of A Luminex Based Competitive Immunoassay for 2, 4, 6-Trinitrotoluene (TNT). Environ. Sci. Technol. 2007, 41 (8), 2888-2893.

(27) Zacco, E.; Pividori, M. I.; Alegret, S.; Galvé, R.; Marco, M.-P. Electrochemical Mmagnetoimmunosensing Strategy for the Detection of Pesticides Residues. Anal. Chem. 2006, 78 (6), 1780-1788.

(28) Zhang, L.; Zhao, J.; Duan, M.; Zhang, H.; Jiang, J.; Yu, R. Inhibition of dsDNA-Templated Copper Nanoparticles by Pyrophosphate as A Label-Free Fluorescent Strategy for Alkaline Phosphatase Assay. Anal. Chem. 2013, 85 (8), 3797-3801.

(29) Jang, H.; Lee, J.; Min, D.-H. Graphene Oxide for FluorescenceMediated Enzymatic Activity Assays. J. Mater. Chem. B 2014, 2 (17), $2452-2460$

(30) Deng, J.; Yu, P.; Wang, Y.; Mao, L. Real-Time Ratiometric Fluorescent Assay for Alkaline Phosphatase Activity with Stimulus Responsive Infinite Coordination Polymer Nanoparticles. Anal. Chem. 2015, 87 (5), 3080-3086.

(31) Kitamura, M.; Maeda, M.; Tsuji, A. A New Highly Sensitive Chemiluminescent Assay of Alkaline Phosphatase Using Lucigenin and Its Application to Enzyme Immunoassay. J. Biolumin. Chemilumin. 1995, 10 (1), 1-7.

(32) Ruan, C.; Wang, W.; Gu, B. Detection of Alkaline Phosphatase Using Surface-Enhanced Raman Spectroscopy. Anal. Chem. 2006, 78 (10), 3379-3384.

(33) Akanda, M. R.; Tamilavan, V.; Park, S.; Jo, K.; Hyun, M. H.; Yang, H. Hydroquinone Diphosphate as A Phosphatase Substrate in Enzymatic Amplification Combined with Electrochemical-ChemicalChemical Redox Cycling for the Detection of E. coli O157: H7. Anal. Chem. 2013, 85 (3), 1631-1636.

(34) Choi, Y.; Ho, N. H.; Tung, C. H. Sensing Phosphatase Activity by Using Gold Nanoparticles. Angew. Chem., Int. Ed. 2007, 46 (5), 707-709.

(35) Zhao, w.; Chiuman, W.; Lam, J. C. F.; Brook, M. A.; Li, Y. Simple and Rapid Colorimetric Enzyme Sensing Assays Using Non-
Crosslinking Gold Nanoparticle Aggregation. Chem. Commun. 2007, No. 36, 3729-3731.

(36) Li, C. M.; Zhen, S. J.; Wang, J.; Li, Y. F.; Huang, C. Z. A Gold Nanoparticles-Based Colorimetric Assay for Alkaline Phosphatase Detection with Tunable Dynamic Range. Biosens. Bioelectron. 2013, 43, 366-371.

(37) Xianyu, Y.; Wang, Z.; Jiang, X. A Plasmonic Nanosensor for Immunoassay via Enzyme-Triggered Click Chemistry. ACS Nano 2014, 8 (12), 12741-12747.

(38) Gao, Z.; Deng, K.; Wang, X.-D.; Miró, M.; Tang, D. HighResolution Colorimetric Assay for Rapid Visual Readout of Phosphatase Activity Based on Gold/Silver Core/Shell Nanorod. ACS Appl. Mater. Interfaces 2014, 6 (20), 18243-18250.

(39) Liang, R.-Q.; Tan, C.-Y.; Ruan, K.-C. Colorimetric Detection of Protein Microarrays Based on Nanogold Probe Coupled with Silver Enhancement. J. Immunol. Methods 2004, 285 (2), 157-163.

(40) Wang, C.; Ma, Z.; Wang, T.; Su, Z. Synthesis, Assembly, and Biofunctionalization of Silica-Coated Gold Nanorods for Colorimetric Biosensing. Adv. Funct. Mater. 2006, 16 (13), 1673-1678.

(41) Li, H.; Wang, C.; Ma, Z.; Su, Z. Colorimetric Detection of Immunoglobulin $\mathrm{G}$ by Use of Functionalized Gold Nanoparticles on Polyethylenimine Film. Anal. Bioanal. Chem. 2006, 384 (7-8), 15181524.

(42) Mao, X.; Jiang, J.; Luo, Y.; Shen, G.; Yu, R. Copper-Enhanced Gold Nanoparticle Tags for Electrochemical Stripping Detection of Human IgG. Talanta 2007, 73 (3), 420-424.

(43) Zhong, Z.; Li, M.; Xiang, D.; Dai, N.; Qing, Y.; Wang, D.; Tang, D. Signal Amplification of Electrochemical Immunosensor for the Detection of Human Serum IgG Using Double-Codified Nanosilica Particles as Labels. Biosens. Bioelectron. 2009, 24 (7), 2246-2249.

(44) Chen, Z.-P.; Peng, Z.-F.; Luo, Y.; Qu, B.; Jiang, J.-H.; Zhang, X.B.; Shen, G.-L.; Yu, R.-Q. Successively Amplified Electrochemical Immunoassay Based on Biocatalytic Deposition of Silver Nanoparticles and Silver Enhancement. Biosens. Bioelectron. 2007, 23 (4), 485-491.

(45) Liu, D.; Wang, Z.; Jin, A.; Huang, X.; Sun, X.; Wang, F.; Yan, Q.; Ge, S.; Xia, N.; Niu, G.; Liu, G.; Walker, A. R. H.; Chen, X. Acetylcholinesterase-Catalyzed Hydrolysis Allows Ultrasensitive Detection of Pathogens with the Naked Eye. Angew. Chem., Int. Ed. 2013, 52 (52), 14065-14069.

(46) Chen, H.; Shao, L.; Li, Q.; Wang, J. Gold Nanorods and Their Plasmonic Properties. Chem. Soc. Rev. 2013, 42 (7), 2679-2724.

(47) Wang, J.; Li, Y. F.; Huang, C. Z. Identification of Iodine-Induced Morphological Transformation of Gold Nanorods. J. Phys. Chem. C 2008, 112 (31), 11691-11695.

(48) Wang, J.; Wu, H.; Huang, C. Investigations on the Amalgamation of Gold Nanorods by Iodine and the Detection of Tetracycline. Sci. China, Ser. B: Chem. 2009, 52 (2), 188-195.

(49) Liu, J.-M.; Jiao, L.; Cui, M.-L.; Lin, L.-P.; Wang, X.-X.; Zheng, Z.-Y.; Zhang, L.-H.; Jiang, S.-L. A Highly Sensitive Non-Aggregation Colorimetric Sensor for the Determination of $\mathrm{I}^{-}$Based on Its Catalytic Effect on $\mathrm{Fe}^{3+}$ Etching Gold Nanorods. Sens. Actuators, B 2013, 188, 644-650.

(50) Zhang, Z.; Chen, Z.; Chen, L. Ultrasensitive Visual Sensing of Molybdate Based on Enzymatic-Like Etching of Gold Nanorods. Langmuir 2015, 31 (33), 9253-9259.

(51) Zhang, Z.; Chen, Z.; Wang, S.; Qu, C.; Chen, L. On-Site Visual Detection of Hydrogen Sulfide in Air Based on Enhancing the Stability of Gold Nanoparticles. ACS Appl. Mater. Interfaces 2014, 6 (9), 63006307.

(52) Jackson, T.; Ekins, R. Theoretical Limitations on Immunoassay Sensitivity: Current Practice and Potential Advantages of Fluorescent $\mathrm{Eu}^{3+}$ Chelates as Non-Radioisotopic Tracers. J. Immunol. Methods 1986, 87 (1), 13-20.

(53) Liu, D.; Yang, J.; Wang, H.-F.; Wang, Z.; Huang, X.; Wang, Z.; Niu, G.; Hight Walker, A.; Chen, X. Glucose Oxidase-Catalyzed Growth of Gold Nanoparticles Enables Quantitative Detection of Attomolar Cancer Biomarkers. Anal. Chem. 2014, 86 (12), 58005806. 
(54) Nie, X.-M.; Huang, R.; Dong, C.-X.; Tang, L.-J.; Gui, R.; Jiang, J.-H. Plasmonic ELISA for the Ultrasensitive Detection of Treponema Pallidum. Biosens. Bioelectron. 2014, 58, 314-319. 